\title{
Justification of the underflow intake design in the mountainous gardening conditions for the drip irrigation system
}

\author{
Kharlampiy Kilidi ${ }^{1}$, Evgeny Kuznetsov ${ }^{1}$, Anna Khadzhidi $^{1}$, Larisa Motornaya ${ }^{1}$, Arsen \\ Kurtnezirov ${ }^{1}$, and Lyudmila Kravchenko, ${ }^{2, *}$ \\ ${ }^{1}$ Kuban State Agrarian University named after I. T. Trubilina, 350044, Kalinina str, 13, Russia \\ ${ }^{2}$ Don State Technical University, 344003, 1. Gagarin sq., Rostov-on-Don, Russia
}

\begin{abstract}
For ecological gardening, it is necessary to develop agricultural landscapes, which are currently not used effectively enough in mountainous areas and are not adapted for the production of eco-products, except for hay on pastures. Drip irrigation systems allow you to grow orchards and vineyards on the slopes of mountains and areas with high slopes. The source of irrigation for orchards is usually mountain rivers, which have an unstable water regime due to flood events, which is a problem for the development of ecological gardening and viticulture. Designed water intake structure on the White river for drip irrigation systems, which in a complex hydrological regime source of irrigation ensures the production of water for irrigation of crops, and allows at minimum levels to provide the necessary water supply for irrigation of crops in the highlands of the North Caucasus. The design for extracting irrigation water includes perforated polyethylene pipes with a flushing device located in a trench in the backfill of the filter. Water purified from large deposits flows by gravity into the receiving well and is then sent to an additional treatment system. This approach to water extraction provides a guaranteed irrigation regime for the garden of fruit crops.
\end{abstract}

\section{Introduction}

For ecological gardening, it is necessary to develop agricultural landscapes, which are currently not used effectively enough in mountainous terrain and are not adapted for the production of eco-products other than hay on pastures. Drip irrigation systems (DI) allow the cultivation of orchards and vineyards on the slopes of mountains and areas with high slopes [1]. However, the issue of water extraction in the required volume for crop irrigation remains difficult [2]. The source of crops irrigation, as a rule, is usually mountain rivers, which have an unstable water regime due to flood events [3]. Extraction, delivery and preparation of water for irrigation is the most problematic issue for the development of ecological gardening and viticulture [4]. Therefore, it is necessary to develop a simple and efficient design for the operation of a water intake structure for a drip irrigation system,

\footnotetext{
*Corresponding author: lusya306@yandex.ru
} 
which, under a complex hydrological regime of an irrigation source, would ensure water production for irrigating crops, which is an urgent problem in mountainous terrain [5]. The design of under-channel water intake on the Belaya river has been developed, which allows, at minimum levels, to provide the required water supply for irrigating crops in the mountainous terrain of the North Caucasus. The structure for irrigation water extraction includes perforated polyethylene pipes with a washing device located in a trench in a filter backfill. When compared with existing structures, the design of the water intake allows to flush the filter pipes simultaneous and take water into the irrigation system without shutting down the pumping units [6]. Thus, water which has been previously cleaned of large sediments enters the receiving well by gravity and is then directed to an additional cleaning system. This approach to water extraction provides a guaranteed irrigation regime for the garden of fruit crops [7].

\section{Research methodology (methods)}

The design of the underflow water intake was developed for the drip system of LLC "Muscat" in the Maykop district of the Republic of Adygea (Figure 1)

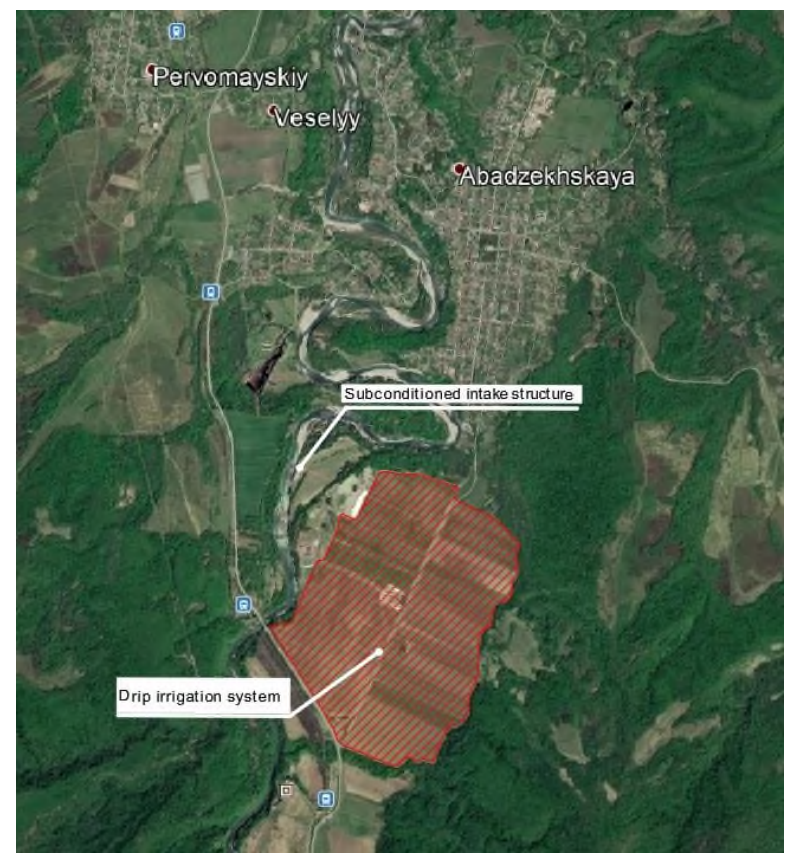

Fig. 1. Scheme of water intake from the Belaya river to the drip irrigation system

The choice of the filter design is determined by the hydrological regime of the river: surface runoff and sediment runoff. A feature of the hydrological regimes is high velocities, shallow depths during low-water periods, bottom sediments and in the flow thickness. The regime is influenced by the tortuosity, rifts and slopes of river sections where water intake structures are designed. According to the river hydrograph, periods of floods and low-water periods were established. The most intense period, both for the river and for the cultivation of crops, is the low water period, which begins to set on the river in August when the gardens need to provide the highest water consumption for the formation of the crop [8]. Therefore, the main task is to extract water from the river during low water periods. 
Hydrometric studies were performed to assess the velocities and depths of the flow at the point of water intake. Three sections were chosen: the first section was located $10 \mathrm{~m}$ above the water intake, the 2nd section was split along the axis perpendicular to the water intake, and the 3 rd section was selected below $10 \mathrm{~m}$ downstream of the 2 nd section. This made it possible to estimate the currents and flow depths of the river during low water periods at a $50 \%$ probability of runoff. The flow rates on the verticals were measured with a micro spinner. The flow depths at the vertical velocity measurement point were determined using a hydrometric rod in 5-fold repetition at $20 \mathrm{~s}$ time intervals synchronously with the flow velocities measurement. Bottom sediments, their size was determined by the hydraulic size of the fractions. The sediment regime and its size determine the design and type of water intake filter. The size of the sediment load depends on the transporting capacity of the flow and the volume of river flow. The most dangerous are drawn sediments [9], which destroy water intake structures in mountainous conditions. At the water intake section, the sediments move in the flow thickness, along the bottom of the riverbed and have an average size of frictions range of 5-300 $\mathrm{mm}$, and there are also sizes of bottom sediments greater than $300 \mathrm{~mm}$.

On the other hand, during floods, which may occur in mountainous areas for a short time and during low-water periods, it is necessary to preserve and ensure the operability of the water intake structure. Therefore, the design of the filter must be performed in such a way that it provides the required water intake for any hydrological regime of the river (flood-low water). This is the main requirement for the reliability in the operation of a water intake structure for the operation of drip irrigation systems.

The morphology of the river section under study is also crucial for justifying the design of the capture filters. The size of the filter in the water intake section is determined by the type of soil of the channel. The bottom of the riverbed is formed by sedimentary morphometric dense rocks, which are practically not eroded. Gravel bottom sediments cover sedimentary rocks and have rounded shapes. The hydraulic and geometric parameters of the structure depend on the flow rate and the size of the slopes in the river. The diameter of the capture pipes is determined by the water supply to the drip irrigation system and is found from the flow formula:

$$
d=(1.1-1.2) Q^{0.5}
$$

Where:

$\mathrm{d}$ is the diameter of the gripping filter pipe, $\mathrm{m}$;

Q- water consumption for the $\mathrm{KO}$ system, m3/s.

The flow of water from the river through the perforation of the filter capture pipe will be determined by the formula:

$$
Q=\mu n \omega_{\text {lane }} \sqrt{2 g Z}
$$

Where:

$\mathrm{Q}$ is the water flow through the filter, $\mathrm{m} 3 / \mathrm{s}$;

$\mu$ is the flow coefficient of the sand and gravel filter;

$\mathrm{n}$ - holes on a perforated pipe;

$\omega$ lane - perforation area, $\mathrm{m} 2$;

$\mathrm{Z}$ - hydraulic level difference in the river and in the receiving chamber of the well, $\mathrm{m}$.

\section{Research results}


The location of water intake from hydrological, morphological conditions, the formation of currents and depths has a number of advantages in relation to the movement of sediments (Figure 2).

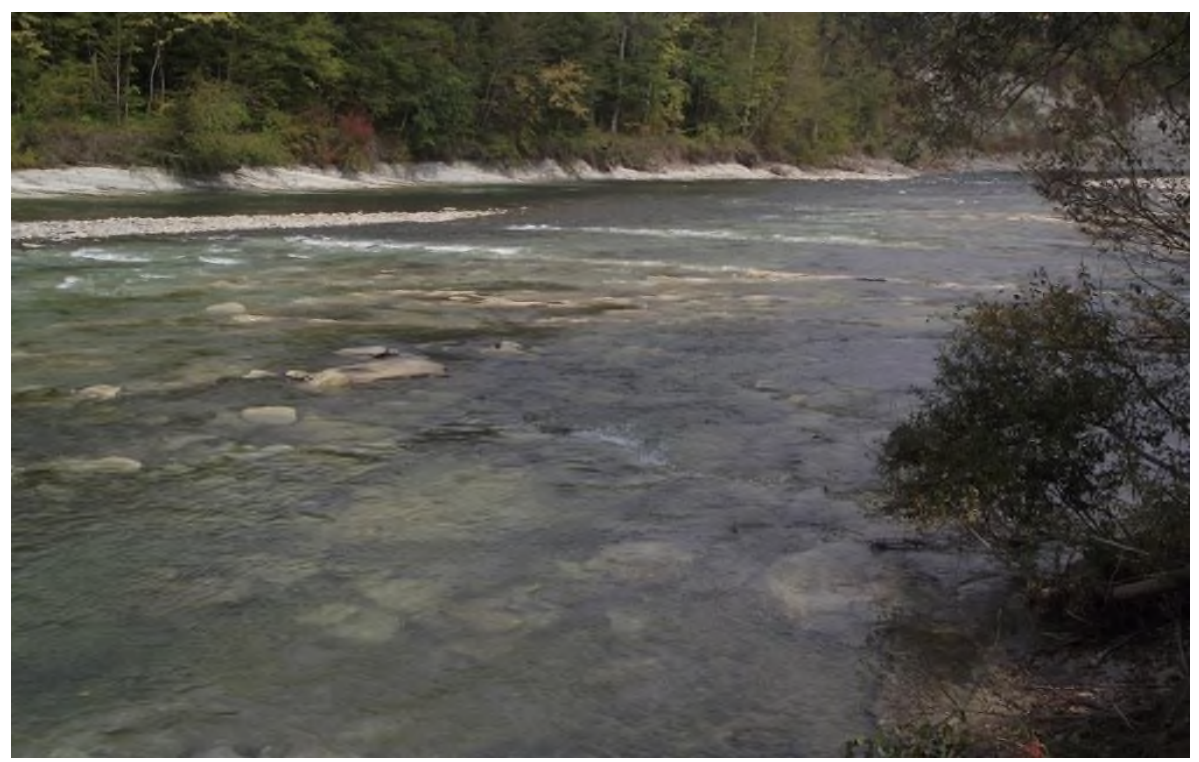

Fig. 2. Section of the Belaya river in the water intake line

As the route survey of the riverbed has shown, the selected section in the water intake line has a number of advantages in the hydrological regime. It is located on the right bank, where there is always a low water level.

The flow from the left bank under the action of centrifugal forces is pressed to the water intake point (Figure 2). It is established that the incoming stream does not erode the channel, because in this section tangent speeds are created due to the flow of the fairway, which is pressed to the right bank due to the turn of the river. The fairway is installed $12 \mathrm{~m}$ from the water intake during low-water periods. The flow velocity in the fairway is 2.0-2.2 $\mathrm{m} / \mathrm{s}$, and the incoming transverse flow velocity is $1.0-1.5 \mathrm{~m} / \mathrm{s}$, this provides natural protection of the water intake site from erosion and sediment deposition. The depths of the flow at the point of water intake varies from $0.1 \mathrm{~m}$ during low-water periods and up to 2-5 $\mathrm{m}$ during floods, depending on the hydrological regime of the river flow.

As a result of the performed studies and analysis of the hydrological regime in the section of water intake into the KO system, it has been established that the underflow intake is the best design. The advantages of underflow water intake: the bottom of the river bed is not eroded; the level above the roof of the water intake is in the range of 0.1-0.5 m during low water periods; the movement of bottom sediments does not affect the conditions for water intake into the irrigation system; floods do not destroy the structure of the filtering (capture) part of the water intake; the biological resources are not negatively affected during the operation of the system; easy installation of filter pipes of the water intake structure.

The design of the underflow water intake into the riverbed trench is shown in Figure 2. For the filter of underflow stable water intake from the river for irrigation, 2 perforated pipes with flushing devices in the form of two pipes of a smaller diameter and cylindrical nozzles are provided, which provide current flushing of the filter by hydraulic jets under pressure ( Figure 2). The diameter of the perforated pipe is determined by the formula (1). The perforated pipe lengths are calculated for the flow rate of one pump. The length of the 
pipe perforation L is calculated from formula (2), where the flow coefficient takes into account the filter contamination with suspended sediments.

A filter is arranged around the pipe, the filter design is shown in Figure 2. For sprinkling the pipe, layers of gravel are taken from the top to the bottom of the trenches: torn stone 300-600 mm; gravel 50-100 $\mathrm{mm} ; 100-150 \mathrm{~mm}$.

Construction of a water intake structure. From the filter part, water flows through perforated pipes into a receiving well of rectangular size in a plan to the underground part of the water intake structure (Figure 3).

Perforated pipes are placed by a truck crane in a trench at the bottom of the river. A reverse filter is arranged around the pipe (Figure 2). At the beginning of the pipe, there are 2 stops made of reinforced concrete, separated by an expansion joint measuring $1.0 \times 1.325 \times 1.0 \mathrm{~m}$. The perforated part of the pipe with the stop is located in the riverbed, the rest of the pipe is in the coastal part. Pipes with a diameter of $500 \mathrm{~mm}$ with a hole pitch of $2.5 \times 2.5 \mathrm{~cm}$ at the other end enter the receiving chamber of the well, where at the inlet of the flow from the pipe there are flat gates that provide water supply to the chamber during the irrigation season. The bottom of the chamber has a slope to the entrance part of the well, where sediments are collected, and the chamber is cleaned.

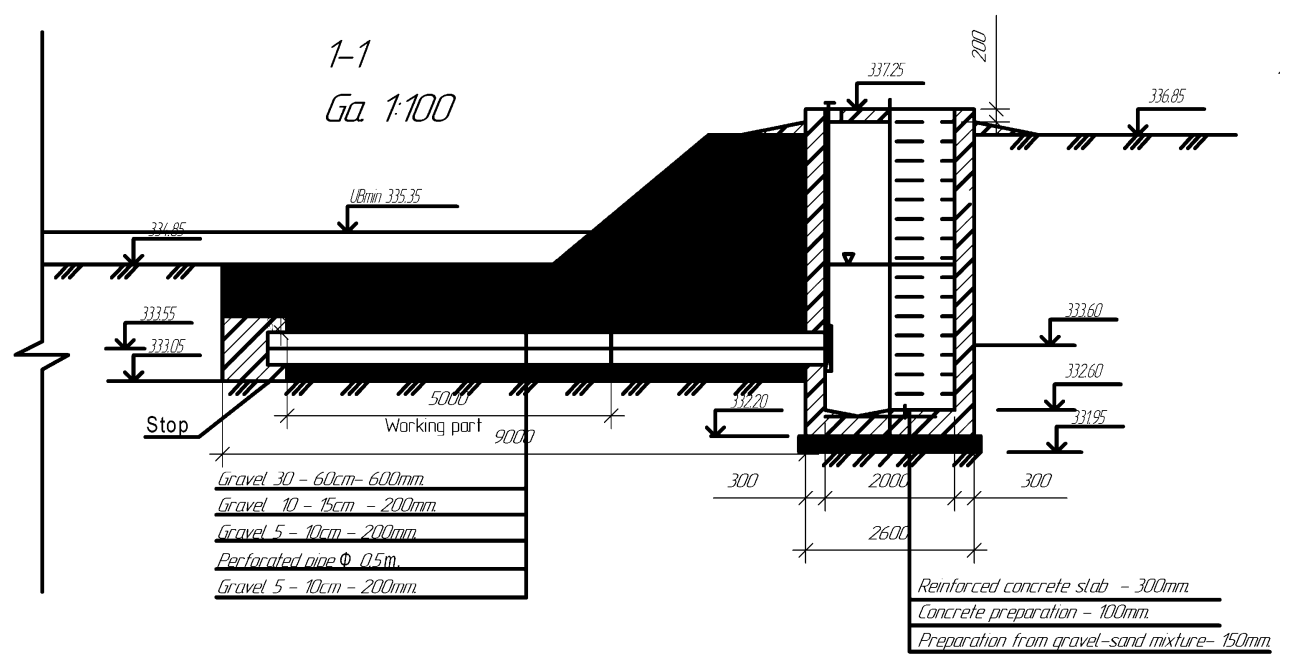

Plan at elevation 333.55

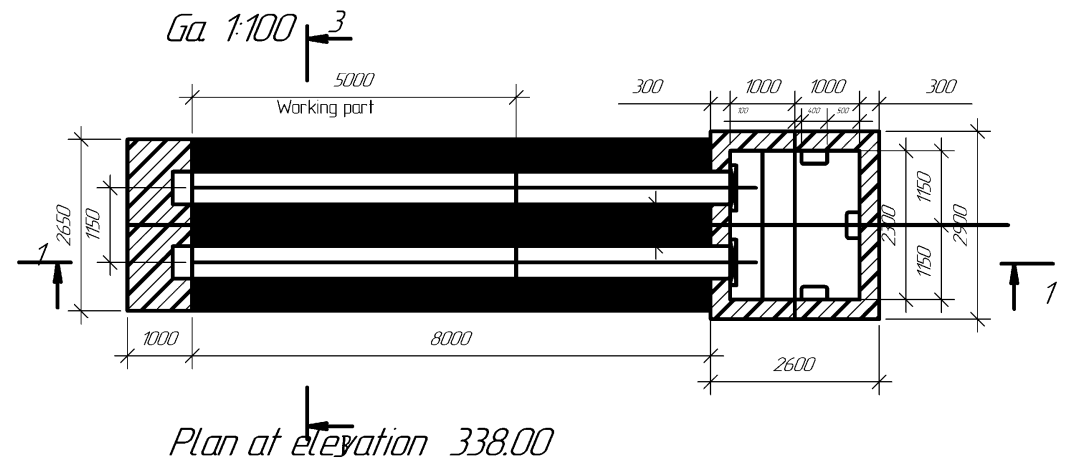

Ga $\quad 1: 100$

Fig. 3. The design of the water intake structure 
Submersible pumps are installed in the well to take water from the river and supply it to the storage pond. 2 pumps are installed in the chamber. Each pump provides the required flow and pressure. The design of the chamber ensures continuous water intake into the irrigation system.

A calculation method has been developed for the developed design of the water intake structure.

The flow capture rate from the river to the trench should not exceed $0.1-0.2 \mathrm{~m} / \mathrm{s}$. This condition protects juvenile (young) fish from death at the water intake. The receiving area of the trench according to the technical standards for the placement of filter pipes is much larger than the area of the outlet openings of the pipes. Therefore, when the water enters the trench, the velocity does not exceed $0.05-0.07 \mathrm{~m} / \mathrm{s}$ and is much ess than the non-critical speed of protection of juveniles.

The diameter of the receiving perforated pipe is calculated from the flow rate at the outlet to the chamber according to the formula (1). The diameter is taken from the condition that the flow velocity at the outlet will be in the range of $0.2-0.3 \mathrm{~m} / \mathrm{s}$. This flow rate is less than the silting speed [10] and the sediment will fall out in the chamber without getting into the irrigation pipelines.

The standard pipe diameter is accepted according to the manufacturer's assortment. The flow rate at the outlet of the perforated pipe is specified according to the formula $\mathrm{V}_{\mathrm{B}}=\mathrm{Q}$ / Фтр., Where

The hydraulic difference between the level in the river and the receiving chamber is being specified. The water flow through the perforation is determined by the formula (2). The number of holes should allow the required water flow for irrigating crops.

\section{Conclusions}

The design of the water intake structure on the Belaya river for a drip irrigation system has been developed, which given the complex hydrological regime of the irrigation source, ensures water production. It has been established that the underflow water intake allows, at minimum levels, to provide the required water supply for irrigating crops in mountainous terrain. A new calculation method for this type of water intake device is proposed.

\section{References}

1. H. Boesveld, L. S. Zisengwe, S. Yakami, Drip Planner Chart: A simple irrigation scheduling tool for smallholder drip farmers. Irrigation and Drainage Systems, 25(4), (2012) DOI: 10.1007/s10795-012-9127-4

2. G. Nigussie, M. A. Moges, M. M. Moges, T. S. Steenhuis, Assessment of Suitable Land for Surface Irrigation in Ungauged Catchments: Blue Nile Basin, Ethiopia, Water, 11(7), 1465 (2019) https://doi.org/10.3390/w11071465

3. I. Boukhanef, A. Khadzhidi and etc., Calibration of Manning's Roughness coefficient during Floods using HEC RAS model. International Journal of Advanced Science and Technology, 29(11), 2184-2197 (2020)

4. A. H. Rabia, H. Figueredo, T. Huong, H. Solomon, V. Geomatics, Land Suitability Analysis for Policy Making Assistance: A GIS Based Land Suitability Comparison between Surface and Drip Irrigation Systems. International Journal of Environmental Science and Development, 4(1) (2013)

5. B. Li1, M. Wang, J. Tang, Research on Extraction Method of River Water from MODIS Image of Mountainous Areas in Western Sichuan and Optimized by DEM 
Data, EMCEME 2019. Conf. Series: Materials Science and Engineering 042047 IOP Publishing (2020) doi:10.1088/1757-899X/782/4/042047

6. M. Wegelin, M. Boller, Particle Removal by Horizontal-Flow Roughing Filtration. Aqua, 3 (2011)

7. W. B. Min, A Method to Identify Water-Body from MODIS Image Data in Upper Reach of Changjiang River [J]. Plateau Meteorology, 23(5), 141-145 (2004)

8. A. W. Worqlul, E. K. Ayana, H. Yen, J. Jeong, T. S. Steenhuis, Evaluating hydrologic responses to soilcharacteristics using SWAT model in a paired-watersheds in the Upper Blue NileBasin, Catena 163, 332-341 (2018)

9. L. Shizhong, C. Jiangping, L. Minghai, A Probability-based Statistical Method To Extract Water Body Of Tm Images With Missing Information, International Society for Photogrammetry and Remote Sensing, 16, 21-26

10. C. Z. Liu, J. C. Shi, S. Gao, L. Chen, Study of the water body extracting from MODIS images based on improved mixed pixel method[J]. Remote Sensing Information, 1, 8488 (2010)

11. L. D. Ding, H. Wu, C. J. Wang, Z. H. Qin, Q. X. Zhang, Study of the water body extracting from MODISimages based on spectrum-photometric method[J]. Geomatics \& Spatial Information Technology, 29(6), 25-27 (2010)

12. C. Justice, J. Townshend, Special issue on the moderate resolution imaging spectroradiometer (MODIS): a new generation of land surface monitoring [J]. Remote Sensing of Environment, 83(1), 1-2 (2002)

13. F. Hui, B. Xu, H. Huang, Q. Yu, P. Gong, Modeling spatial-temporal change of Poyang Lake using multitemporal Landsat imagery[J]. International Journal of Remote Sensing, 29, 5767-5784 (2008)

14. R. Sivanpillai, S. N. Miller, Improvements in mapping water bodies using ASTER data [J]. Ecological Informatics, 5, 73-78 (2010)

15. E. A. Work, D. S. Gilmer, Utilization of satellite data for inventorying prairie ponds and lakes [J]. Photogrammetric Engineering and Remote Sensing, 42, 685-694 (2016) 